\title{
BLADDER TRAINING BERPENGARUH TERHADAP PENURUNAN KEJADIAN INKONTINENSIA URINE PADA PASIEN POST OPERASI BPH DI RUANG RAWAT INAP RSUD SOREANG
}

\author{
Teti Nurhasanah, Ali Hamzah \\ Poltekkes Kemenkes Bandung \\ Email: alihamzahbandung@yahoo.co.id
}

\begin{abstract}
The incidence of benign prostate hyperplasia (BPH) in Indonesia is quite high, which is about 24-30\% of urological cases treated in several central public hospitals. While the incidence of BPH in general hospital Soreang in 2014 shows a fairly high incidence rate $(12.5 \%)$ and the second number of the top ten surgery cases after fibro adenoma mamma. Open prostatectomy is an invasive treatment to help miction of the BPH patients and it can cause side effects especially urinary incontinence. According to the result of preliminary study indicated that $80 \%$ patients who control to Soreang general hospital after open prostatectomy surgery have urinary incontinence. One kind of nursing interventions that can be given to overcome urinary incontinence is by doing bladder training. This study aims to determine the effect of bladder training with use of delay urination and scheduled urination technique to decrease the incidence of urinary incontinence in post operative BPH patients. The research used quasi experiment, with used pre and post test approach in two intervention groups without using control group to 60 samples who obtained by accidental sampling, so the total number of each group is $30 \mathrm{BPH}$ patiens. The results showed that bladder training with both delay urination and scheduled urination techniques had a significant effect on decreasing incidence of urinary incontinence in postoperative BPH patients, but there was no significant difference in the results of the two bladder training techniques on decreasing incidence of urinary incontinence. Related to this result, to prevent urinary incontinence of the post operative BPH patients is suggested to the nurse to apply bladder training with delay urination and scheduled urination techniques and in its application need to considered the age and physical condition of the patient.
\end{abstract}

Keywords: Benign Prostat Hyperplasia, delay urination, scheduled urination, incontinence urine

\section{ABSTRAK}

Insidensi benigna prostat hiperplasia (BPH) di Indonesia cukup tinggi, yaitu sekitar 24-30\% dari kasus urologi yang dirawat di beberapa rumah sakit umum pusat. Sedangkan angka kejadian BPH di RSUD Soreang pada tahun 2014 menunjukkan angka kejadian yang cukup tinggi ( 12,5\%) dan menduduki urutan kedua setelah kasus Fibroma adenoma mammae ( FAM). Pembedahan dengan cara open prostatektomy merupakan tindakan invasif untuk membantu proses pengeluaran urine pasen BPH dan dapat menimbulkan efek samping terutama inkontinensia urine. Hasil studi pendahuluan menunjukkan bahwa $80 \%$ pasen yang kontrol ke poli bedah RSUD Soreang mengalami inkontinensia urine setelah dilakukan open prostatectomy. Salah satu intervensi keperawatan yang dapat dilakukan untuk mengatasi inkontinensia urine adalah dengan melakukan bladder training. Penelitian ini bertujuan untuk mengetahui pengaruh bladder training dengan metode delay urination dan scheduled urination terhadap kejadian inkontinensia urine pada pasien post operasi BPH. Jenis 
penelitian menggunakan quasi eksperimen, dengan pendekatan pre and post test pada dua kelompok intervensi tanpa menggunakan kelompok kontrol dengan jumlah sampel sebanyak 60 pasien post operasi BPH yang diperoleh dengan accidental sampling dengan jumlah masing-masing kelompok 30 orang pasen. Hasil penelitian menunjukkan bahwa bladder training baik dengan teknik delay urination maupun scheduled urination sama-sama memiliki pengaruh signifikan terhadap penurunan kejadian inkontinensia urine pada pasien post operasi BPH, tetapi tidak terdapat perbedaan hasil yang signifikan dari kedua teknik bladder training tersebut terhadap penurunan kejadian inkontinensia urine. Terkait dengan hasil penelitian ini untuk menghindari terjadinya inkontinesia urie pada pasen post operasi BPH disarankan kepada perawat agar menerapkan bladder training dengan teknik delay urination dan scheduled urination dan dalam penerapannya perlu mempertimbangkan usia dan kondisi fisik pasen.

Kata Kunci : Benigna Prostat Hiperplasia, delay urination, scheduled urination, inkontinensia urin.

\section{PENDAHULUAN}

Benigna prostat hiperplasia $(\mathrm{BPH})$ merupakan pembesaran kelenjar prostat yang memanjang ke atas kedalam kandung kemih dan menyumbat aliran urine dengan menutupi orifisium uretra akibatnya terjadi dilatasi ureter (hidroureter) dan ginjal (hidronefrosis) secara bertahap (Smeltzer dan Bare, 2002), yang menyebabkan gangguan fungsi buang air kecil. Proses ini biasanya dimulai pada usia sekitar 35 tahun dan mulai progresif sejalan dengan bertambahnya usia pria (Soenarjo, 2005). Akibatnya maka akan terjadi obstruksi saluran kemih, karena urine tidak mampu melewati prostat sehingga menimbulkan retensio urine, pembentukan batu pada kandung kemih dan apabila tidak segera diobati dapat mengakibatkan gagal ginjal (Sjamsuhidajat dan De jong, 2005).

Penatalaksanaan medik yang sering dilakukan untuk mengatasi masalah kesulitan buang air kencing pada pasien $\mathrm{BPH}$ yaitu dengan pembedahan. Menurut Smeltzer dan Bare (2002) intervensi bedah yang dapat dilakukan meliputi : prostatektomi terbuka dan pembedahan endourologi. Pembedahan prostatektomi terbuka merupakan tindakan yang paling tua yang masih dikerjakan pada saat ini, paling invasif dan paling efisien sebagai terapi BPH tetapi dapat menimbulkan efek samping bagi pasien yaitu terjadinya inkontinensia urine akibat dari insufisiensi sfingter uretra dan disfungsi kandung kemih. Data menunjukkan $56 \%$ dari 52 pasien post operasi BPH mengalami inkontinensia urine setelah 3 bulan akibat disfungsi kandung kemih (Purnomo, 2008). Menurut Campbell-Walsh (2012) kemungkinan disfungsi kandung kemih naik 5,3\% setiap tahun dan pada pasien yang lebih dari usia 70 tahun memiliki resiko dua kali kemungkinan inkontinensia urine pasca operasi. 
Salah satu intervensi nonfarmakologis keperawatan yang bersifat independent dan dapat dilakukan untuk mencegah terjadinya inkontinensia urine antara lain dengan bladder training. Bladder training merupakan upaya mengembalikan pola buang air kecil dengan menghambat atau merangsang keinginan buang air kecil. Melalui tindakan bladder training diharapkan akan mencegah disfungsional, memperbaiki kemampuan untuk menekan urgensi dapat diubah dan secara bertahap akan meningkatkan kapasitas kandung kemih serta memperpanjang interval berkemih ((Kozier, Erb, Berman and Snyder, Alih Bahasa: Esty Wahyuningsih, dkk. (2011). Sri Wulandari (2012) menyatakan bahwa terdapat pengaruh dari latihan bladder training terhadap penurunan inkontinensia pada pasen lanjut usia di Panti Wredha Dharma Bhakti, Surakarta.

Metode bladder training diantaranya adalah delay urination dan scheduled urination. Delay urination adalah latihan menahan/menunda untuk berkemih. Pada pasien yang masih terpasang kateter, delay urination dilakukan dengan mengklem atau mengikat aliran urine ke urine bag. Tindakan ini memungkinkan kandung kemih terisi urine dan otot detrusor berkontraksi sedangkan pelepasan klem memungkinkan kandung kemih untuk mengosongkan isinya Latihan ini dilakukan 6-7 kali per hari sampai pasien dapat menunda untuk berkemih. Sedangkan Scheduled urination adalah pembiasaan berkemih sesuai dengan jadwal yang telah dibuat oleh perawat 6-7 kali perhari, jadwal tersebut harus diikuti dengan ketat oleh pasien, sehingga pasien berhasil belajar kembali mengenal dan mengadakan respon yang sesuai terhadap keinginan untuk berkemih (Smeltzer, 2002).

Menurut Indrajaya dalam Purnomo (2008) insidensi BPH di Indonesia cukup tinggi, yaitu sekitar 24-30\% kasus urologi yang dirawat di beberapa rumah sakit umum pusat. Insidensi BPH di Rumah Sakit Cipto Mangunkusumo dalam kurun waktu 1994-1997 ada 462 kasus, sedangkan di Rumah Sakit Hasan Sadikin Bandung dalam kurun waktu 1976-1985 ada 1.185 kasus. Selanjutnya di R.S. Dr Soetomo Surabaya dalam rentang 10 tahun terakhir (1993-2002) tercatat 1.948 kasus dan di R.S. Sumber Waras ada 602 kasus pada rentang waktu yang sama. Data terbaru mengenai angka kejadian BPH di beberapa Rumah Sakit di Indonesia sampai saat ini belum didapatkan secara pasti. Sedangkan data rekam medik Rumah Sakit Umum Daerah Soreang pada tahun 2014 menunjukkan angka kejadian operasi BPH 
berjumlah 160 orang pasen dan menempati urutan kedua terbanyak setelah operasi Fibroma Adenoma Mamae (FAM). Semua pasien BPH tersebut setelah dioperasi dipasang kateter dan mengalami inkontinensia urine.

Penelitian ini bertujuan untuk mengetahui pengaruh bladder training dengan metode delay urination dan scheduled urination serta perbedaan dari kedua metoda tersebut terhadap kejadian inkontinensia urine pada pasien post operasi BPH. Penelitian ini berbeda dengan penelitian yang telah dilakukan sebelumnya yaitu ingin lebih fokus mengidentifikasi perbedaan keefektipan dari 2 jenis metoda bladder training tersebut terhadap penurunan kejadian inkontinesia urine, sehingga hasilnya diharapkan dapat diaplikasikan oleh perawat pada saat merawat pasen post operasi $\mathrm{BPH}$ agar resiko terjadinya inkontinesia urine dapat dicegah/dihindari sehingga kualitas layanan asuhan keperawatan meningkat.

\section{METODE}

Penelitian ini menggunakan quasi eksperimen dengan desain pre and post test pada dua kelompok intervensi, yaitu 1 kelompok dilakukan intervensi bladder training dengan metode delay urination dan kelompok pasien yang lain dilakukan bladder training dengan metode scheduled urination kepada pasen post operasi open prostatectomy yang dirawat di RSUD Soreang. Sebanyak 60 orang responden telah berpartisipasi dalam penelitian ini yang didapatkan dengan teknik accidental sampling. Jumlah sampel tersebut ditetapkan berdasarkan hasil perhitungan dengan menggunakan rumus uji hipotesis beda rata-rata 2 kelompok berpasangan (Sudigdo, 2008), kemudian untuk masingmasing kelompok ditetapkan secara proporsional yaitu masing-masing 30 orang dan untuk mencegah bias dari intervensi yang diberikan, kedua kelompok tersebut dipisahkan oleh ruangan yang berbeda. Kelompok pasen yang diberikan perlakuan dengan metode delay urination adalah pasien post operasi BPH yang dirawat di ruang Mawar dan diberi perlakuan berupa latihan menunda berkemih dengan cara mengikat/mengklem dan melepaskan kembali slang folley cateter nya sebanyak 7 kali per hari dari pagi sampai dengan sore hari setelah proses irigasi urine selesai (urine sudah berwarna jernih) sampai pasen dapat merasakan dan menunda keinginan berkemih. Sedangkan untuk kelompok yang dilakukan metode scheduled urination adalah pasien yang dirawat di ruang Flamboyan, diberikan perlakuan berupa pembiasaan berkemih sesuai dengan jadwal yang telah dibuat oleh 
perawat sebanyak 7 kali perhari, jadwal tersebut harus diikuti dengan ketat oleh pasien sampai pasen dapat mengenal dan mengadakan respon yang sesuai terhadap keinginan untuk berkemih.

Instrumen yang digunakan dalam penelitian ini ada 2 yaitu :

a. Instruksi latihan delay urination dan scheduled urination yang diberikan kepada pasien post operasi BPH. Instrumen dibuat oleh peneliti dengan merujuk pada buku Toto Suharyanto (2008) karena sampai saat ini di RSUD Soreang belum ada atau belum dibuat SOP tentang Bladder Training.

b. Kuesioner tentang kejadian Inkontinensia urine, dengan menggunakan pertanyaan tertutup yang berisi sejumlah pertanyaan dan pilihan jawaban nya "ya" atau "tidak". Pertanyaan yang ditanyakan tentang bisa tidaknya pasien merasakan dan menahan keinginan buang air kecil setelah pasien tersebut menjalani latihan Bladder Training dengan delay urination atau scheduled urination.

Pengumpulan data dilakukan setelah mendapatkan izin (ethical clearance) dari tim kaji etik RSUD Soreang dan dilakukan selama 2 bulan yaitu bulan April s.d Mei tahun 2015, dengan langkah-langkah sebagai berikut:
1) Melakukan persamaan persepsi dan melatih perawat yang akan membantu dalam pelaksanaan penelitian terkait dengan langkah-langkah dalam SOP dari kedua intervensi.

2) Melakukan inform consent kepada responden dan keluarga, dilanjutkan dengan pengambilan data pre test.

3) Melakukan intervensi sesuai dengan SOP yang telah dibuat, yaitu:

a) Pada pasien post operasi BPH yang dirawat di ruang Mawar dilakukan latihan delay urination pada hari ke 3-6 pasien post operasi BPH atas persetujuan Dokter. Latihan dilakukan sebanyak 7 kali perhari dimulai dari kemampuan menahan buang air kecil selama 1 jam pada hari ketiga post operasi selanjutnya dilanjutkan dengan menahan buang air kecil 2 jam dan seterusnya ditingkatkan lebih lama kemampuan menahan buang air kecilnya pada hari-hari berikutnya.

b) Sedangkan untuk pasien post operasi $\mathrm{BPH}$ yang dirawat di ruang Flamboyan dilakukan latihan scheduled urination pada hari ke $3-6$ atas persetujuan Dokter. Latihan dimulai pada bangun tidur pagi kemudian dilakukan jadwal berkemih 2-3 jam sepanjang siang sampai sore hari, serta setiap 4 jam sekali pada 
malam hari dengan melibatkan peran serta keluarga pasien.

4) Pada hari ke-7 sebelum pasien pulang dilakukan pengambilan data post test.

Data yang sudah terkumpul kemudian dianalisa dengan analisa univariat yaitu menggunakan rumus prosentase. Selanjutnya dilakukan analisa bivariate dengan menggunakan 2 jenis test non parametrik, yaitu: uji wilcoxon signed rank dan test Mann Whitney U.

\section{HASIL DAN PEMBAHASAN}

1) Gambaran Umum Karakteristik Pasien

Tabel 1. Gambaran Umum Karakteristik Pasien

\begin{tabular}{|c|c|c|}
\hline Karakteristik Pasien & $\mathrm{f}$ & $\%$ \\
\hline $\begin{array}{l}\text { Berdasarkan Usia: } \\
\qquad \quad<40 \text { tahun } \\
\text { - } 40-55 \text { tahun } \\
\text { - } \quad>56 \text { tahun }\end{array}$ & $\begin{array}{c}8 \\
19 \\
33\end{array}$ & $\begin{array}{l}13,3 \\
31,7 \\
55,0\end{array}$ \\
\hline Jumlah & 60 & 100 \\
\hline $\begin{array}{l}\text { Berdasarkan Pekerjaan: } \\
\text { - Karyawan swasta } \\
\text { - PNS } \\
\text { - Pensiunan / Tidak bekerja }\end{array}$ & $\begin{array}{l}28 \\
11 \\
21\end{array}$ & $\begin{array}{l}46,7 \\
18,3 \\
35,0\end{array}$ \\
\hline Jumlah & 60 & 100 \\
\hline $\begin{array}{cl}\text { Berdasarkan Pendidikan: } \\
\text { - } & \text { Dasar (SD dan SMP) } \\
\text { - } & \text { Menengah (SLTA) } \\
\text { - } & \text { Perguruan tinggi }\end{array}$ & $\begin{array}{l}21 \\
25 \\
14\end{array}$ & $\begin{array}{l}35,0 \\
41,7 \\
23,3\end{array}$ \\
\hline Jumlah & 60 & 100 \\
\hline
\end{tabular}

Tabel 1 memberikan gambaran karakteristik pasien yaitu sebagian besar pasien $(55,0 \%)$ berusia lebih dari 56 tahun, yang hampir sebagian nya $(46,7 \%)$ mempunyai pekerjaan sebagai karyawan swasta dan kebanyakan (35,0\%) tidak bekerja, serta hampir sebagian diantaranya $(41,7 \%)$ berpendidikan menengah (SLTA) diikuti oleh berpendidikan dasar $(35,0 \%)$ dan hanya sebagian kecil (23,3 \%) yang berpendidikan tinggi.

Hasil penelitian menunjukan gambaran kondisi inkontinensia urine pada pasien post operasi BPH sebelum dilakukan delay urination maupun scheduled urination, seluruh pasien 
mengalami inkontinensia urine. Inkontinensia urine merupakan komplikasi umum pada pasien post operasi BPH, terutama operasi prostatektomi terbuka akibat dari insufisiensi sfingter uretra dan disfungsi kandung kemih. Setelah dilakukan latihan delay urination pada pasien yang dirawat di ruang Mawar diketahui hampir sebagian pasien sudah mengalami perbaikan dengan tidak lagi mengalami inkontinensia urine, sedangkan pada pasien yang dilakukan latihan scheduled urination diketahui setengah dari jumlah pasien sudah mengalami perbaikan dan tidak lagi mengalami inkontinensia urine.

Hasil ini sesuai dengan hasil penelitian sebelumnya yang dilakukan oleh Reza Pamungkas, Nurhayati dan Musiana (2013) yang menyatakan bahwa bladder training berpengaruh terhadap interval berkemih Lansia yang mengalami inkontinensia urine di UPTD PSLU Tresna Werdha Bakti Yuswa Provinsi Lampung $(p=0.000)$. Wulan (2013) dalam Lucky Angelia Shabrini, Ismonah, dan Syamsul Arif (2015) mengemukakan bahwa terdapat pengaruh yang signifikan dari bladder training terhadap pasen yang terpasang kateter urin.
Latihan delay urination yang diterapkan pada pasien post operasi hasilnya menunjukkan lebih sedikit yang berhasil dibandingkan dengan pasien yang diberikan intervensi scheduled urination. Perbaikan dengan latihan delay urination lebih lambat/lebih sulit hal tersebut disebabkan oleh faktor usia dimana sebagian besar pasien berusia lebih dari 55 tahun. Proses pengembalian spingter uretra akan lebih lambat dibandingkan pengembalian otot dibawah usia kurang dari 55 tahun. Hasil penelitian ini sesuai temuan Bayhakki (2008) dalam Lucky Angelia Shabrini, Ismonah, dan Syamsul Arif (2015) yang menyatakan bahwa usia/umur merupakan salah satu faktor yang mempengaruhi keberhasilan dari intervensi bladder training terhadap kecepatan waktu berkemih. Selain faktor usia tingkat pendidikan juga mempengaruhi daya tangkap pasien untuk menerima instruksi SOP delay urination dari perawat dimana hampir sebagian pasien berpendidikan SMA dan berpendidikan dasar (SD dan SMP) sehingga latihan/intervensi tidak maksimal meskipun sudah diberi tahu berulang-ulang dan sudah dibekali dengan SOP. 
2) Gambaran Kondisi Inkontinensia Urine sebelum dan sesudah dilakukan intervensi Delay Urination dan Scheduled Urination

\section{Tabel 2. Gambaran Kondisi Inkontinensia Urine sebelum dan sesudah dilakukan intervensi delay urination dan sesudah scheduled urination}

\begin{tabular}{ccccccccc}
\hline \multirow{3}{*}{$\begin{array}{c}\text { Jenis Intervensi } \\
\text { Bladder Training }\end{array}$} & \multicolumn{4}{c}{ Kondisi fungsi saluran perkemihan pasen } \\
\cline { 2 - 9 } & \multicolumn{3}{c}{ Inkontinensia } & \multicolumn{3}{c}{ Tidak Inkontinensia } \\
\cline { 2 - 9 } & \multicolumn{2}{c}{ Pre Test } & Post test & Pre Test & \multicolumn{2}{c}{ Post test } \\
\cline { 2 - 9 } & f & $\%$ & f & $\%$ & f & $\%$ & $\mathrm{f}$ & $\%$ \\
\hline - Delay urination & 30 & 100 & 19 & 63,3 & 0 & 0 & 11 & 36,7 \\
- Scheduled urination & 30 & 100 & 15 & 50,0 & 0 & 0 & 15 & 50,0 \\
\hline
\end{tabular}

Berdasarkan Tabel 2 diatas tampak gambaran kondisi inkontinensia urine sebelum dan sesudah intervensi delay urination, diketahui seluruh pasien $(100 \%)$ mengalami inkontinensia urine sebelum dilakukan intervensi delay urination, dan setelah dilakukan intervensi delay urination diketahui sebagian besar pasien $(63,3 \%)$ masih mengalami kejadian inkontinensia urine dan hampir sebagian pasien $(36,7 \%)$ mengalami perbaikkan yaitu dengan tidak menderita inkontinensia urine lagi. Gambaran kondisi inkontinensia urine sebelum dan sesudah intervensi scheduled urination, juga tidak jauh berbeda yaitu seluruh pasien (100\%) mengalami inkontinensia urine sebelum dilakukan intervensi scheduled urination pengaruh delay urination terhadap penurunan kejadian inkontinensia urine pada pasien post operasi BPH di Ruang Rawat Inap RSUD Soreang $(p=0.001)$

Scheduled urination adalah metode untuk melatih pengembalian fungsi syaraf otot-otot berkemih dengan cara menentukan jadwal untuk berkemih, dan jadwal tersebut harus diikuti dengan ketat oleh pasien, sehingga pasien berhasil dan setelah dilakukan intervensi scheduled urination diketahui setengah dari jumlah pasien (50\%) masih mengalami inkontinensia urine dan setengah lagi $(50 \%)$ sudah tidak mengalami inkontinensia urine lagi.

Delay urination adalah metode dengan melakukan latihan menahan kencing/menunda untuk berkemih. Pada pasien yang masih terpasang kateter, delay urination dilakukan dengan mengklem atau mengikat aliran urine ke urine bag.Tindakan ini memungkinkan kandung kemih terisi urine dan otot detrusor berkontraksi sedangkan pelepasan klem memungkinkan kandung kemih untuk mengosongkan isinya (Smeltzer, 2002). Hasil penelitian menunjukkan terdapat 
belajar kembali mengenal dan mengadakan respons yang sesuai terhadap keinginan untuk berkemih. Setelah dilakukan latihan scheduled urination pada pasien post operasi $\mathrm{BPH}$ yang dirawat ruang Flamboyan, diketahui bahwa setengah dari jumlah pasien sudah tidak lagi mengalami inkontinensia urine dan sebagian nya lagi masih mengalami inkontinensia urine. Analisa menggunakan uji Wilcoxon diketahui terdapat pengaruh scheduled urination terhadap penurunan kejadian inkontinensia urine pada pasien post operasi BPH di RSUD Soreang $(\mathrm{p}=0.000)$

Hasil penelitian ini sesuai dengan penelitian yang dilakukan oleh Sri
Wulandari (2012) yang menyatakan bahwa terdapat pengaruh dari latihan bladder training terhadap penurunan inkontinensia pada pasen lanjut usia di Panti Wredha Dharma Bhakti, Surakarta. Hasil penelitian ini kemudian diperkuat oleh hasil penelitian yang dilakukan oleh Ngesti W. Utami (2016) tentang pengaruh latihan bladder training terhadap fungsi perkemihan pada pasen post operasi dengan spinal anesthesi, yang menunjukkan bahwa bladder training berpengaruh secara significant terhadap pengembalian fungsi perkemihan pada pasen post operasi tersebut $(\mathrm{p}=0,000)$.

3) Pengaruh Intervensi delay urination dan Scheduled Urination terhadap penurunan kejadian inkontinensia urine pada pasien post operasi BPH di RSUD Soreang.

Tabel 3. Hasil Uji Wilcoxon pengaruh delay urination dan Scheduled Urination terhadap penurunan kejadian inkontinensia urine pada pasien post operasi BPH

\begin{tabular}{lcccc}
\hline Jenis Intervensi & $N$ & Mean Rank & Z-score & p-value \\
\hline - $\quad$ delay urination & 30 & 6 & $-3,317$ & 0,001 \\
\hline - Scheduled Urination & 30 & 8 & $-3,873$ & 0,000 \\
\hline
\end{tabular}

Tabel 3 merupakan hasil test wilcoxon signed rank yang menunjukkan bahwa kedua intervensi yaitu delay urination dan scheduled urination masingmasing secara signifikan berpengaruh dapat menurunkan kejadian inkontinensia pada pasien post operasi BPH. Intervensi dengan delay urination menghasilkan nilai
$\mathrm{Z}$ score $-3,317$ dan $p$-value sebesar 0,001 sedangkan dengan intervensi scheduled urination menghasilkan $\mathrm{Z}$ score -3,873 dan $p$-value $=0,000 . \quad$ Hal ini menunjukkan bahwa kedua jenis metoda bladder training ini dapat menurunkan kejadian inkontinesia urine pada pasen post open prostatectomy di rumah sakit. 
4) Perbedaan antara intevensi delay urination dengan scheduled urination terhadap penurunan kejadian inkontinensia urine pada pasien post operasi BPH di RSUD Soreang

Tabel 4. Hasil Test Mann-Whitney U Perbedaan antara Delay Urination dengan Scheduled urination

\begin{tabular}{|c|c|c|c|c|}
\hline Metode & $\mathrm{N}$ & Mean Rank & $Z$-score & $p$-value \\
\hline - Delay Urination & 30 & 32,50 & \multirow{2}{*}{$-1,033$} & \multirow{2}{*}{0,301} \\
\hline Scheduled Urination & 30 & 28,50 & & \\
\hline
\end{tabular}

Berdasarkan hasil analisa test Mann Whitney U pada tabel 4 di atas dapat diketahui bahwa nilai Mean Rank intervensi dengan delay urination adalah 32,50 sedangkan dengan intervensi scheduled urination adalah 28,50 dengan nilai $\mathrm{Z}$ score sebesar $-1,033$ dan $p$-value $=$ 0,301 ( $\mathrm{p}$ value $\geq 0.05$ ). Hal ini menunjukkan bahwa tidak terdapat perbedaan pengaruh antara intervensi delay urination dengan scheduled urination terhadap penurunan kejadian inkontinensia urine pada pasien post operasi BPH di RSUD Soreang. Tidak adanya perbedaan pengaruh dari kedua metode tersebut menunjukkan bahwa kedua jenis metode bladder training samasama dapat digunakan dan baik untuk diimplementasikan sebagai upaya mencegah terjadinya inkontinensia urine sedikit dibandingkan kelompok dengan intervensi scheduled urination. Hal ini menunjukkan bahwa kedua latihan tersebut dapat diterapkan dan dilakukan pada pasien post operasi BPH agar tidak mengalami inkontinensia urine. Hanya dalam memilih dan menentukan intervensi delay urination atau scheduled urination yang akan dilakukan pada pasien, perawat perlu mempertimbangkan usia dan pada pasien post operasi open prostatectomy dan hasil ini konsisten atau sejalan dengan hasil analisa wilcoxon signed rank pada tabel 3.

Hasil uji statistik dengan menggunakan test Mann Whitney U menunjukkan bahwa antara delay urination dengan scheduled urination tidak terdapat perbedaan antara delay urination dengan scheduled urination ( $p=$ 0.301) terhadap penurunan kejadian inkontinensia urine. Hasil ini menunjukkan bahwa meskipun secara statistik tidak terdapat perbedaan antara intervensi dengan delay urination dengan scheduled urination tetapi apabila dilihat secara klinis diantara keduanya terdapat perbedaan yaitu jumlah pasien yang mengalami perbaikkan pada kelompok dengan intervensi delay urination lebih kemampuan pasien dalam hal memahami petunjuk SOP yang diberikan oleh perawat. 
Pada pasien yang usianya lebih tua dan kemampuan memahami petunjuk SOP kurang (pendidikan rendah) sebaiknya menggunakan metode scheduled urination, karena pasien tinggal mengikuti jadwal yang sudah ditentukan dan bisa dibantu oleh keluarga. Sedangkan bagi pasien yang lebih muda dan relatif bisa memahami instruksi dapat digunakan metode delay urination .

Melalui latihan delay urination dan scheduled urination, memberikan dampak positif bagi pasien post operasi $\mathrm{BPH}$ di Ruang Rawat Inap RSUD Soreang, sehingga dapat mengembalikan fungsi kandung kemih yang mengalami gangguan dan merupakan upaya mengembalikan pola buang air kecil dengan menghambat atau merangsang keinginan buang air kecil, sehingga dengan dilakukannya latihan tersebut dapat menekan terjadinya inkontinensia urine.

\section{SIMPULAN}

1. Terdapat pengaruh intervensi bladder training baik dengan metoda delay urination maupun scheduled urination terhadap penurunan kejadian inkontinensia urine pada pasien post operasi BPH di RSUD Soreang.

2. Tidak terdapat perbedaan pengaruh secara signifikan antara intervensi bladder training baik dengan delay urination maupun dengan scheduled urination terhadap penurunan kejadian inkontinensia urine pada pasien post operasi BPH di RSUD Soreang.

Merujuk pada hasil dan simpulan penelitian, terdapat beberapa rekomendasi yang perlu disampaikan, yaitu:

1. Bagi Komite Keperawatan Rumah Sakit Umum Daerah Soreang diharapkan untuk membuat SOP bladder training khususnya dengan metode delay urination dan scheduled urination, kemudian mengeluarkan kebijakan agar kedua metode bladder training tersebut dapat diaplikasikan/diterapkan kepada pasien post operasi BPH dan mengevaluasi pelaksanaan nya.

2. Bagi perawat yang bekerja di ruang rawat inap bedah RSUD Soreang disarankan untuk mengaplikasikan intervensi bladder training dengan metode delay urination atau scheduled urination kepada pasen post operasi BPH sebagai intervensi nonfarmakologis untuk mencegah terjadinya inkontinensia urine. Penerapannya perlu mempertimbangkan faktor usia dan kemampuan pasien dalam menerima informasi/instruksi dari perawat. Bagi pasien yang masih muda dan bisa memahami instruksi dalam SOP sebaiknya menggunakan metode delay urination sedangkan bagi pasien yang kurang 
memahami instruksi sebaiknya menggunakan scheduled urination.

3. Bagi peneliti selanjutnya dimohon untuk dapat meneliti lebih lanjut terkait dengan faktor-faktor yang berpengaruh terhadap keberhasilan tindakan bladder training dalam mencegah terjadinya inkontinensia urine dan atau menggunakan sample yang berbeda dengan jumlah sample yang lebih banyak.

\section{DAFTAR RUJUKAN}

Arif Muttaqin. 2008. Asuhan Keperawatan Gangguan Sistem Perkemihan, Jakarta, PT. Salemba Medika.

Campbell-Walsh. 2012. Urology $10^{\text {th }}$ Edition, Philadelphia, WB Saunders and imprint of Elsevier Inc.

Dharma, Kelana kusuma. 2011. Metodologi Penelitian Keperawatan, Jakarta : Trans Info Media.

Indrajaya, Mayasari. 2007. Skripsi: Prevalensi Hiperplasia Prostat di Rumah Sakit Immanuel Bandung Periode Januari 2004-Desember 2006, Bandung : Universitas Kristen Maranatha.

Kozier, Erb, Berman and Snyder, Alih Bahasa: Esty Wahyuningsih, dkk. 2011. Buku Ajar Fundamental Keperawatan: konsep, Proses dan Praktik, edisi 7, volume 2. Jakarta, EGC

Lucky Angelia Shabrini, Ismonah, Syamsul Arif. 2015. Efektifitas Bladder Training Sejak Dini dan
Sebelum Pelepasan Kateter Urin Terhadap Terjadinya Inkontinensia Urine Pada Pasen Paska Operasi Di SMC RS Telogorejo, Jurnal Ilmu Keperawatan dan Kebidanan (JIKK), volume II, nomor 3 (144 - 151), Semarang.

Ngesti W. Utami. 2016. Pengaruh Bladder Training terhadap Fungsi Perkemihan pasen Post Operasi dengan Spinal Anesthesi, Jurnal Pendidikan Kesehatan, volume 5, nomor 2 (107 - 114), Malang.

Notoatmojo, S. 2010. Metodologi Penelitian Kesehatan. Jakarta. Rineka Cipta.

Potter dan Perry. 2005. Fundamental Perawatan, Edisi IV, Jakarta :EGC.

Purnomo, Basuki B. 2008. Dasar-dasar Urology, Jakarta : CV Sagung Seto.

Reza Pamungkas, Nurhayati, Musiana. 2013. Pengaruh Latihan Kandung Kemih (Bladder Training) terhadap Interval Berkemih Wanita Lanjut Usia (Lansia) dengan Inkontinensia Urin, Jurnal Keperawatan, volume IX, Nomor 2 (214-219), Lampung.

Sjamsuhidajat dan De jong. 2005. Buku Ajar Ilmu Bedah, Jakarta : EGC.

Sri Wulandari, Agus Sudariyanto, Agustaria Budiana. 2012. Skripsi: Pengaruh Bladder Training terhadap Penurunan Inkontinensia Pada Lanjut Usia di Panti Dharma Bhakti, Surakarta, Surakarta: Universitas Muhammadiyah Surakarta. 
Sudigdo. 2008. Metodologi Penelitian

Kesehatan, Jakarta : Rineka Cipta.

Sugiyono. 2010. Pengolahan Data

Statistik. Bandung. Alfabet.
Suharyanto, Toto. 2008. Asuhan Keperawatan pada Klien dengan Gangguan Sistem Perkemihan. Jakarta. Trans Info Me.

Susan C. Smeltzer alih Bahasa: Devi Yulianti dan Amelia Kimin. 2015. Keperawatan Medikal Bedah Brunner \& Suddarth, edisi 12, Jakarta, EGC. 
